\title{
IGNACIO DOMEYKO Y LAS BELLAS ARTES
}

\section{INTRODUCCIÓN}

La historiografía ha prestado atención a la actividad del científico polaco Ignacio Domeyko como de fundador de la mineralogía en Chile, reformador del Instituto Nacional y sucesor de Andrés Bello en la rectoría de la Universidad de Chile, entre otros aspectos. El propósito del presente texto es analizar la poco conocida vinculación de Domeyko con las Bellas Artes. Esta dimensión del científico polaco, radicado en Chile desde 1838, se puede observar en su actividad como dibujante, su condición de amante de las artes y propietario de obras, su labor como promotor de la educación artística en Chile y sus ideas en torno a la función de las artes en la vida social.

Domeyko nació en Niedźwiadka Wielka en 1802 y a los catorce años ingresó a estudiar física y matemáticas en la Universidad de Vilna (Amunátegui 6). Más tarde, las convulsiones políticas polacas le impidieron continuar sus estudios y ya en 1830 participaría de la insurrección, incorporándose poco después a las tropas lideradas por el general Dezydery Chłapowski (Amunátegui 7). Su compromiso político lo obligó a refugiarse en Francia, a donde partió con el poeta Mickiewicz, con quien había trabado amistad durante sus años en Vilna (Amunátegui 8). En París completó sus estudios, obteniendo su titulación en la Escuela de Minas en 1837. Ese mismo año fue contactado para hacerse cargo de fundar el curso de química y mineralogía en el Colegio de La Serena, en el norte de Chile (Amunátegui 9-19).

Marcela Drien, Doctora en Historia del Arte - Universidad Adolfo Ibáñez, Santiago, Chile, Facultad de Artes Liberales, Departamento de Historia y Ciencias Sociales, Centro de Estudios del Patrimonio; e-mail: mdrien@uai.cl; ORCID: https://orcid.org/0000-0001-9386-7022.

Fernando Guzmán, Doctor en Historia del Arte, Profesor Titular - Universidad Adolfo Ibáñez, Penalolen, Chile, Facultad de Artes Liberales, Departamento de Historia y Ciencias Sociales; e-mail: fernando.guzman@uai.cl; ORCID: https://orcid.org/0000-0002-6515-8074. 
Luego de cinco años en la ciudad de La Serena se trasladó a Santiago para hacerse cargo de reformar la enseñanza en el Instituto Nacional (Amunátegui 37). En esta institución asumiría más tarde como delegado universitario, aportando desde ese cargo el desarrollo de diversas disciplinas. En 1843 se fundó la Universidad de Chile, ese mismo año Domeyko se incorporó a la Facultad de Ciencias Matemáticas y Físicas, ocupando inmediatamente el cargo de secretario de esa corporación (Amunátegui 45). En 1867 fue designado rector de la Universidad, cargo que desempeñó hasta 1883.

Todas estas responsabilidades docentes y administrativas convivieron con una intensa actividad de investigación científica cuyos resultados se contienen en numerosas publicaciones. Sin embargo, la relevancia de estas dimensiones ha impedido prestar suficiente atención a su inclinación por la Bellas Artes, cuyas manifestaciones se pueden observar a lo largo de toda su vida.

\section{DOMEYKO DIBUJANTE}

El estudio de la trayectoria del polaco Ignacio Domeyko ha estado vinculada preferentemente a su labor científica, pasando por alto la relación que durante gran parte de su vida estableció con el arte tanto desde el punto de vista de la reflexión como de la ejecución. De ahí que resulte necesario realizar una nueva revisión de su vida bajo este prisma.

El arte fue una constante preocupación del científico. A lo largo de los años, Domeyko realizó una serie de dibujos que se vincularon no solo con su labor científica, sino con distintos momentos de su vida, tal como se precia en el contexto de algunos de los homenajes que se le dedicaran tras su muerte, en 1889. Elocuentes resultan algunos artículos que le dedicara el escultor José Miguel Blanco en El Taller Ilustrado, en que fue posible apreciar la relación que el artista había establecido tempranamente con el arte. Un episodio destacado por Blanco se refería precisamente a los dibujos realizados por el científico:

La mano firme que el estudiante de Vilna trazaba a los 20 años, primero a lápiz i en seguida pluma, el retrato del Príncipe Negro, 65 años mas tarde fijaba en el papel las ruinas de la casa de su amigo, el gran poeta Adam Mickiewicz, como piadoso i último tributo rendido a su memoria. I jsingular coincidencia! esas ruinas, recuerdo sagrado para todo polaco amante de la libertad de su patria, meses mas tarde se derribaban por completo hasta no quedar de ellas piedra sobre piedra...Se diría que por aguardar la llegada del ilustre sabio, luchaban desespe- 
radas contra la acción destructora del tiempo, a fin de que pudiera contemplarlas en toda la majestad de su solitaria grandeza, antes de confundirse con el polvo mismo del cual un día se alzaron gallardas sirviendo la mansión paterna al poeta mártir i compañero de armas de nuestro querido Domeyko. ("Don Ignacio Domeyko II”)

El dibujo al que se refiere Blanco, publicado en la portada del periódico con el título La casa del poeta Adams Mickewicz i el príncipe negro (Fig. 1), habría sido realizado por Domeyko a los 85 años, es decir, solo un par de años antes de su muerte. El dibujo, de acuerdo al artículo, había sido publicado también en Polonia:

Las ruinas dibujadas por la mano temblorosa del venerable anciano son su último dibujo, su última obra, el último rasgo de su genio enciclopédico. La casa de Adam Mickiewicz, tal cual hoy la damos a nuestros lectores, ha sido publicada en el Klosy, periódico ilustrado que ve la luz en Varsovia, acompañada de una extensa carta de puño y letra del señor Domeyko, la cual sentimos no poder traducir. ("Don Ignacio Domeyko II")

Al mismo período podría corresponder el dibujo realizado por Domeyko de la casa de su familia (Fig. 2), en la última visita que haría a Polonia.

En el ámbito de la práctica científica, Domeyko había realizado dibujos como parte del proceso de registro y documentación en los viajes que realizó a lo largo de Chile. Tal como lo señalaba Blanco, el polaco había realizado una serie de dibujos en sus viajes a la región de Arauco representando tipos indígenas, cerros y volcanes, que no llegaron a publicarse. A juicio de Blanco “si cuando Domeyko publicó La araucanía i sus habitantes, el grabado o la litografía hubieran estado siguiera a la altura en que hoy se encuentran en el país, esta obra habría aparecido ilustrada por su mismo autor". En efecto, la publicación mencionada por Blanco, editada en 1846, no incluyó ninguna de las láminas mencionadas, limitando así las posibilidades de difusión de su faceta como dibujante.

Sin embargo, Blanco destacaba en este punto, el valor de estos dibujos no solo desde una perspectiva científica, sino desde el punto de vista de la calidad artística de sus obras, al punto de enfatizar la importancia de preservarlos en una colección pública, aunque notablemente, no se refería a una institución de carácter científico, sino artístico: "A nuestro juicio, esos dibujos deben ser adquiridos por el gobierno para enriquecer nuestro Museo Nacional de Bellas Artes, pues valen tanto para Chile como los de Víctor Hugo para la Francia republicana." ("Don Ignacio Domeyko II"). La propuesta de 
Blanco dejaba en claro su interés en inscribir a Domeyko por su destreza artística, más allá de los temas representados en sus dibujos.

Al corpus de obras mencionado hasta aquí por Blanco se agregaría la que identificó como la mayor obra del científico polaco. Se trataba de un dibujo elaborado por Domeyko en Polonia:

Pero la obra maestra del sabio, en materia de dibujo, es una copia a pluma de un cuadro cuyo autor i asunto no conocemos. El asunto debe ser religioso porque está pintado al fresco en las murallas del convento de los padres franciscanos en Vilna. El joven Domeyko entretenía los días de su prisión haciendo esa copia con toda la paciencia i escrupulosidad del artista que empieza su carrera inspirado por la ambición de gloria. ("Don Ignacio Domeyko II")

El dibujo, que a diferencia del primero mencionado no fue publicado en El Taller Ilustrado, se habría realizado posiblemente en el marco del levantamiento político que había tenido lugar en Polonia en 1831 y que habría llevado a Domeyko al exilio en Francia, desde donde llegaría a Chile en 1838. En cuanto al interés del polaco por temas artísticos como este, puede explicarse también por la formación religiosa inculcada tempranamente en el seno familiar (Ryn 39-41).

\section{DOMEYKO Y LAS ARTES}

La práctica del dibujo estuvo conectada con una sólida cultura artística. No se trataba solo del cultivo de un oficio para el que tenía facilidades, sino de un interés más amplio que se fundaba en una formación humanista y estética (Feliú Cruz 22). La activa participación del polaco en el movimiento literario de 1842, así como sus estrechos vínculos con el escultor José Miguel Blanco, son manifestaciones de su amplitud de intereses.

La antigua relación entre Blanco y Domeyko se remontaba a los años de estudiante del escultor, en que la vocación de educador del científico se manifestó aún fuera del ámbito de las ciencias. El escultor chileno testimonia su amor por las bellas artes y su constante interés por el avance de los estudiantes de pintura y escultura, casi como si fueran sus propios alumnos ("Don Ignacio Domeyko I").

Blanco también recordaba el apoyo que Domeyko había brindado a los propios artistas: 
Los que comenzamos nuestro aprendizaje por aquella época, jamás olvidaremos los consejos paternales i las palabras de aliento que constantemente recibíamos del ilustre sabio, cuando, fastidiado a veces por nuestra algazara, tan propia de aquella edad juvenil, se dirigía hacia nosotros desde su laboratorio, para hacernos entrar en vereda. ("Don Ignacio Domeyko I")

Blanco se encargaría de recordar a los lectores de su periódico la larga amistad que los unía, transcribiendo la dedicatoria que le hiciera el científico al reverso de una fotografía dos semanas antes de su muerte: "Para el Sr. Don José Miguel Blanco, su antiguo amigo Ignacio Domeyko." De este vínculo podría haber surgido también el busto, que representando a un Domeyko maduro (Fig. 3), realizara Blanco del octogenario científico en 1884.

La amistad entre ambos había perdurado a lo largo de los años. Pocos días antes de su muerte, Domeyko le hablaba de la colección de arte que había formado a lo largo de los años y que daba cuenta de la amplitud sus intereses artísticos:

No hace todavía tres semanas, nos hablaba de artes i nos mostraba la pequeña colección de cuadros que sus modestos recursos le permitieron traer del Viejo Mundo, junto con dos hermosas fotografías que de sus obras le obsequió un amigo pintor en la querida Polonia.

Cuando modelábamos su busto, nos decía: 'Si yo no me hubiera dedicado a las matemáticas, en Paris, donde frecuentaba el trato de tantos artistas, me habría entregado con pasión a la pintura i a la escultura a la vez. ("Don Ignacio Domeyko II")

En sus viajes por Europa, el científico había adquirido cerca de veinte copias y esculturas, entre los que se encontraban la copia de cuadros identificados como Virgen de Bartolomé Esteban Murillo (1618-1862), y una copia realizada por Carnavalli de El Mendigo también de Murillo, cuyo original posiblemente había apreciado en el Museo del Louvre, durante su estadía en París. Además, había adquirido Peregrino del pintor flamenco Peter Jacob Horemans (1700-1776) y un busto retrato de Rembrandt, de autor no identificado, junto de dos pequeñas marinas y paisajes que Domeyko ubicaría en su salón principal (“Don Ignacio Domeyko II”).

\section{DOMEYKO Y LA EDUCACIÓN ARTÍSTICA EN CHILE}

Diversos indicios permiten afirmar que la formación en Chile de arquitectos, pintores y escultores fue una preocupación constante en Ignacio Do- 
meyko (Lastarria 89). En su Memoria sobre el modo mas conveniente de reformar la instrucción pública, afirma, luego de proponer el modo de articular la Universidad y el Instituto Nacional, que "con el tiempo el Gobierno no dejaría de agregar una quinta facultad de literatura y bellas artes, compuesta de las cátedras de literatura antigua, id moderna, academia de pintura, id de música" (Domeyko, "Memoria" 218). Desde su cargo de Delegado Universitario debió influir directamente en la consolidación de la Academia de Pintura, así como en la creación del curso de escultura y arquitectura ("Don Ignacio Domeyko I"). Una carta de julio de 1867 da cuenta de la atención que prestaba a las Bellas Artes desde su responsabilidad en la sección universitaria del Instituto Nacional; el documento describe el estado de los ramos de arquitectura, pintura, dibujo y escultura, aportando, además, antecedentes precisos acerca de los pensionados que se encontraban perfeccionando sus estudios en París (Domeyko, "Carta 1867").

La atención que le prestaba a las Bellas Artes parece haber obedecido a una inclinación personal, no solo al cumplimiento de sus deberes como funcionario público. Así lo testimonia José Miguel Blanco en El Taller Ilustrado: "nos consideraba como a sus propios discípulos, porque amaba las bellezas del arte tanto como los secretos de la ciencia que inculcaba en sus jóvenes alumnos" ("Don Ignacio Domeyko I"). El escultor chileno señalaba que los visitaba con mucha frecuencia, oportunidades en la que conversaban sobre arte. En estos diálogos, de los que no quedan registros, Domeyko debió referirse a sus preferencias y concepciones, forjadas muy probablemente en las tertulias que sostendría en París con Chopin, o con el poeta Mickiewicz, con quienes compartió su condición de refugiado (Lastarria 32-40).

\section{SUS IDEAS ACERCA DEL ARTE}

Uno de los pocos documentos que permiten indagar en torno a las ideas artísticas del científico polaco es el discurso que pronunció al incorporarse a la Facultad de Filosofía y Humanidades. El 8 de enero de 1867 se realizó en la Universidad de Chile la ceremonia de incorporación de Ignacio Domeyko a la Facultad de Filosofía y Humanidades. El científico polaco venía a llenar el puesto que había quedado vacante al morir Andrés Bello en 1865 (Jofré Berrios 60). La costumbre indicaba que el nuevo integrante de la corporación académica debía realizar un discurso en homenaje al miembro fallecido. Al comenzar a hablar se disculpó por su acento extranjero y por no referirse 
directamente a los méritos de Bello. Su disertación, publicada en los Anales de la Universidad de Chile, se titula "Ciencia, literatura y bellas artes, relación que entre ellas existe" (Domeyko, "Ciencia"; Zalewski 24-25). Si bien el texto enfatiza las referencias a las dos primeras disciplinas, su contenido entrega claves significativas para conocer la concepción que Domeyko tenía de la pintura y la escultura.

El punto de partida de la reflexión es la idea de Humboldt, contenida en su obra Cosmos, acerca de la necesidad de buscar una convergencia entre la razón y la imaginación para comprender cabalmente a la naturaleza (Jofré Berrios 61-62). El conocimiento pleno de la creación no se alcanzaría solo con el rigor de la ciencia, era necesario contar con la poesía, la música y la pintura para avanzar en una comprensión totalizante (Domeyko, "Ciencia" 7). De esta primera premisa se deduce una mutua dependencia de la ciencia y el arte, la primera necesita de la subjetividad de la segunda para lograr sus objetivos, mientras el arte y la poesía podrían adquirir mayor potencia si logran aproximarse al conocimiento que aporta la biología o la química.

La idea de que la poesía y la pintura pueden nutrirse del conocimiento científico constituye el hilo conductor de una buena parte del texto de Domeyko. Luego de ilustrar con numerosos ejemplos la conveniencia de que los artistas conozcan los adelantos de la mineralogía, la zoología y la astronomía, exclama con entusiasmo: “¡cuánto ganaria toda bella inspiracion poética en la contemplación de la naturaleza, si el hombre de letras estuviera iniciado en la averiguación de las fuerzas ocultas i en las causas de los fenómenos que nos rodean diariamente i con que nos familiarizamos desde la edad más tierna!" (Domeyko, "Ciencia" 15).

Pero no se trataría solo de que pintores y poetas conozcan los avances científicos, sería necesario, además, que quienes realizan estas actividades se imbuyeran de sus principios y procedimientos. De tal modo que las obras más plenas serían aquellas que junto con ser el fruto de la inspiración subjetiva, poseyeran rigor y exactitud (Jofré Berrios 62). Una cierta disciplina sería condición para que la imaginación y el genio se encauzaran para producir una obra plena (Domeyko, "Ciencia" 16-17). La ciencia y el arte buscan la verdad y para ello requieren rigor e inspiración. La correcta articulación de razón y subjetividad haría posible la consecución de la verdad, del bien, y de la belleza, elementos trascendentales a los cuales se dirigiría, en último término, la actividad humana. De lo contario la obra artística se corrompe o pierde gran parte de su valía. Domeyko afirmaba "siempre que la literatura, la poesia, las bellas-artes, desconociendo su vocacion i alto destino, se 
limitan a cuidar la forma i el adorno exterior; cuando solamente cuentan con el efecto i se esfuerzan en producir emociones o no tienen otra ambicion que la de agradar, distraer, asaltar el alma, producirán todavía literatos, poetas, artistas laboriosos, bien remunerados, no inútiles por cierto; pero sus producciones estarán lejos de cimentar aquella union a que aspira Humboldt" (Domeyko, "Ciencia" 20). Al coronar este punto menciona a Haydn, Mozart y Rafael Sanzio, como artistas que habrían logrado esa deseada plenitud.

$\mathrm{Su}$ aprecio por la sinceridad de la observación de la naturaleza y su rechazo a los alardes puramente formales quedó también expresado en una carta dirigida a José Santiago Aldunate:

Mas provecho talvez resultaria de que aquel hijo entusiasta por su país, a la vuelta de sus viajes nos dejara en un estilo claro, aunque todavía mas incorrecto que el mio, lo que habrá visto en sus incursiones, que lo que resulta de muchos escritos correctos, pero secos i desabridos, amoldados en aquellas formas exóticas que nos vienen de afuera. (Domeyko, "Carta 1845" 50-51)

Al finalizar el discurso Domeyko se refiere al carácter religioso que tendría la elevación colaborativa de la ciencia y el arte, pues, la articulación de la razón y la imaginación conducen la actividad humana por el camino de lo sublime (Jofré Berrios 67-68). De este modo, la máxima elevación de la pintura, la escultura, la música y la poesía se lograría nutriéndose del conocimiento del Creador. El científico y el artista cristiano, por tanto, deberían cultivar y promover un constante diálogo entre sus actividades, la fe en Dios y la Revelación Divina (Domeyko, "Ciencia” 20-23).

\section{BIBLIOGRAFÍA}

“Don Ignacio Domeyko I". El Taller Ilustrado, 28 de enero de 1889.

“Don Ignacio Domeyko II". El Taller Ilustrado, 4 de febrero de 1889.

Amunátegui, Miguel Luis. Ignacio Domeyko. Imprenta de la República, 1867.

Domeyko, Ignacio. "Carta de Ignacio Domeyko al Ministro de Instrucción Pública, 8 de julio de 1867". Anales de la Universidad de Chile, núm. 29, 1867, pp. 549-553.

Domeyko, Ignacio. "Carta del 27 de octubre de 1845 a José Santiago Alduante”. Miguel Luis Amunátegui. Ignacio Domeyko. Imprenta de la República, 1867.

Domeyko, Ignacio. "Ciencia, literatura y bellas artes, relación que entre ellas existe". Anales de la Universidad de Chile, núm. 1, 1867, pp. 3-23.

Domeyko, Ignacio. "Memoria sobre el modo mas conveniente de reformar la instrucción pública”. El Seminario de Santiago, núm. 27, 5 de enero 1843, pp. 217-219. 
Feliú Cruz, Guillermo. "Domeyko en la evolución cultural de Chile". Anales de la Universidad de Chile, núm. 90-92, 1953, pp. 10-23.

Jofré Berríos, Manuel. "Ciencia, literatura, arte y religión en Domeyko". Anales de la Universidad de Chile, núm. 14, 2002, pp. 59-69.

Lastarria, Berta. Ignacio Domeyko y su época: 1882-1888: héroe e ilustre polaco, sabio eminente, hijo adoptivo de Chile. Sociedad Impr. y Litogr. Universo, 1937.

Ryn, Zdzislaw Jan. "La personalidad de Ignacio Domeyko". Anales de la Universidad de Chile, núm. 14, 2002, pp. 39-45.

Zalewski, Maciej. "Discurso en el Salón de Honor el 31 de julio de 1952". Anales de la Universidad de Chile, núm. 90-92, 1953, pp. 24-30.

\section{IGNACIO DOMEYKO Y BELLAS ARTES}

Resumen

La historiografía ha prestado atención a la actividad del científico polaco Ignacio Domeyko como de fundador de la mineralogía en Chile, reformador del Instituto Nacional y sucesor de Andrés Bello en la rectoría de la Universidad de Chile. El propósito del presente texto es analizar la poco conocida vinculación de Domeyko con las Bellas Artes. Esta dimensión del científico polaco, radicado en Chile desde 1838, se puede observar en su actividad como dibujante, su condición de amante de las artes y propietario de obras, su labor como promotor de la educación artística en Chile y sus ideas en torno a la función de las artes en la vida social.

Palabras clave: Ignacio Domeyko; arte; educación artística; dibujos; Chile.

\section{IGNACY DOMEYKO I SZTUKI PIĘKNE}

\section{Streszczenie}

Polski uczony Ignacy Domeyko zapisał się w historiografii przede wszystkim jako założyciel mineralogii w Chile, reformator Instytutu Narodowego i następca Andresa Bello na stanowisku rektora Universidad de Chile. Celem niniejszej pracy jest analiza, słabo jak dotąd zbadanych, związków Domeyki ze sztuką. Ten wymiar aktywności polskiego uczonego, związanego na stałe z Chile od 1838 r., znalazł odbicie przede wszystkim w jego rysunkach, zainteresowaniu sztuką i kolekcjonowaniu dzieł, a także w pracy na rzecz promowania edukacji artystycznej w Chile i w jego poglądach na temat funkcji sztuki w życiu społecznym.

Słowa kluczowe: Ignacy Domeyko; sztuka; edukacja artystyczna; rysunki; Chile.

\section{IGNACY DOMEYKO AND THE FINE ARTS}

\section{S u m m a ry}

The Polish scientist Ignacy Domeyko made his name in historiography primarily as the founder of mineralogy in Chile, as one of the reformers of the Chilean National Institute, and as the successor to Andres Bello as rector of the Universidad de Chile. The aim of this study is to analyse Domeyko's connections with art, which have been hitherto poorly researched. This area 
of his activity, which was permanently linked to Chile since 1838 , was reflected primarily in his drawings, interest in art and collection of works of art, as well as in his efforts to promote artistic education in Chile and his views on the function of art in social life.

Keywords: Ignacy Domeyko; art; artistic education; drawings; Chile. 


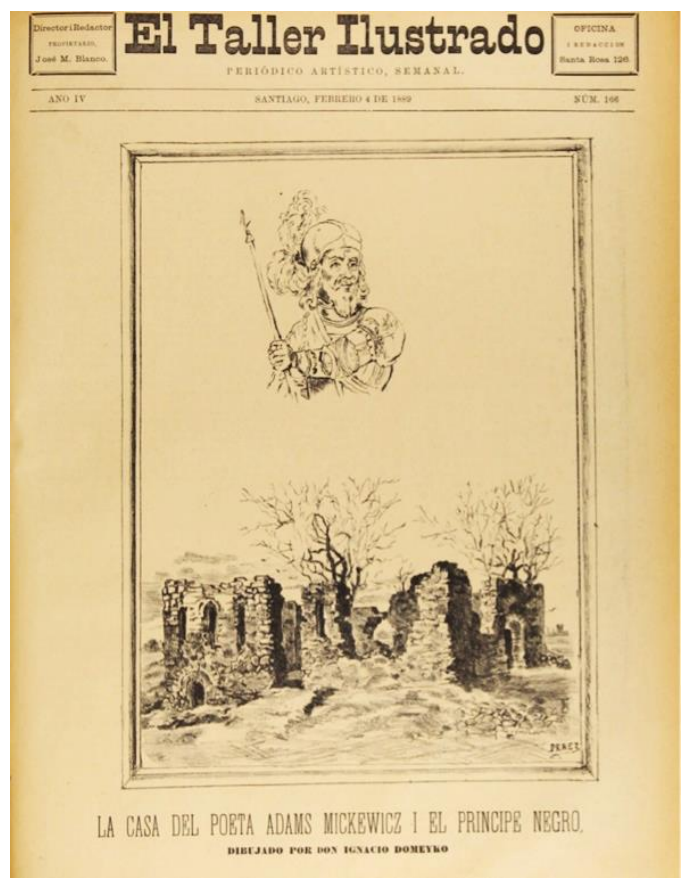

1. La casa del Poeta Adam Mickiewicz y el Príncipe Negro,

dibujado por don Ignacio Domeyko, Portada El Taller Ilustrado, 4 de ferebro de 1889. Memoria Chilena, Biblioteca Nacional de Chile

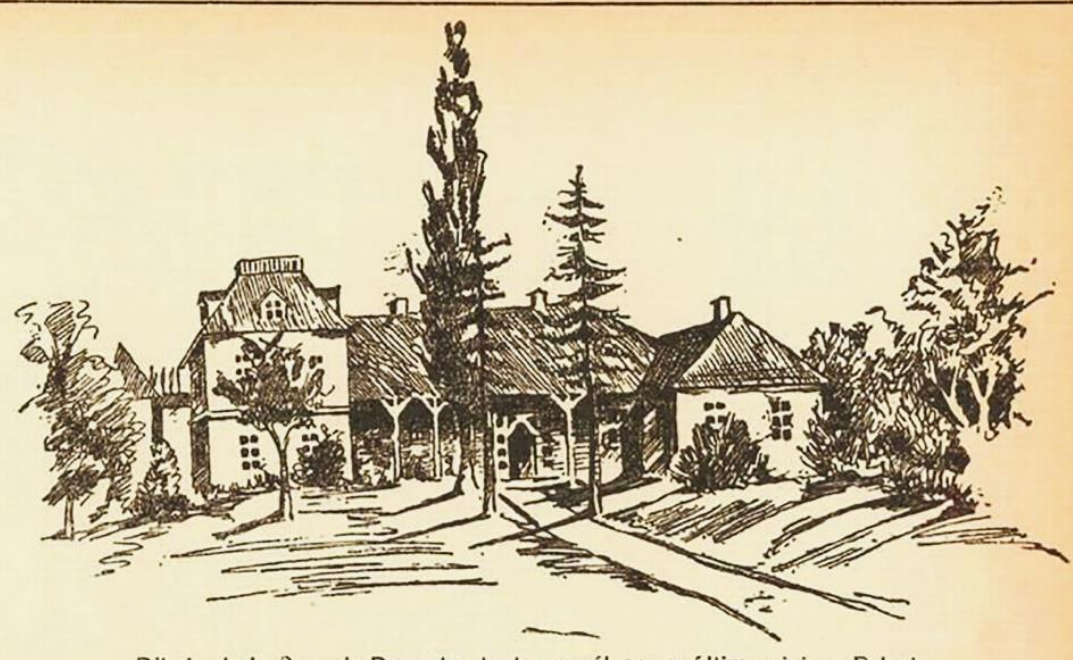

Dibujo de la Casa de Domeyko, hecho por él en su último viaje a Polonia.

2. Dibujo de la casa de Ignacio Domeyko, hecho por él en su último viaje a Polonia 


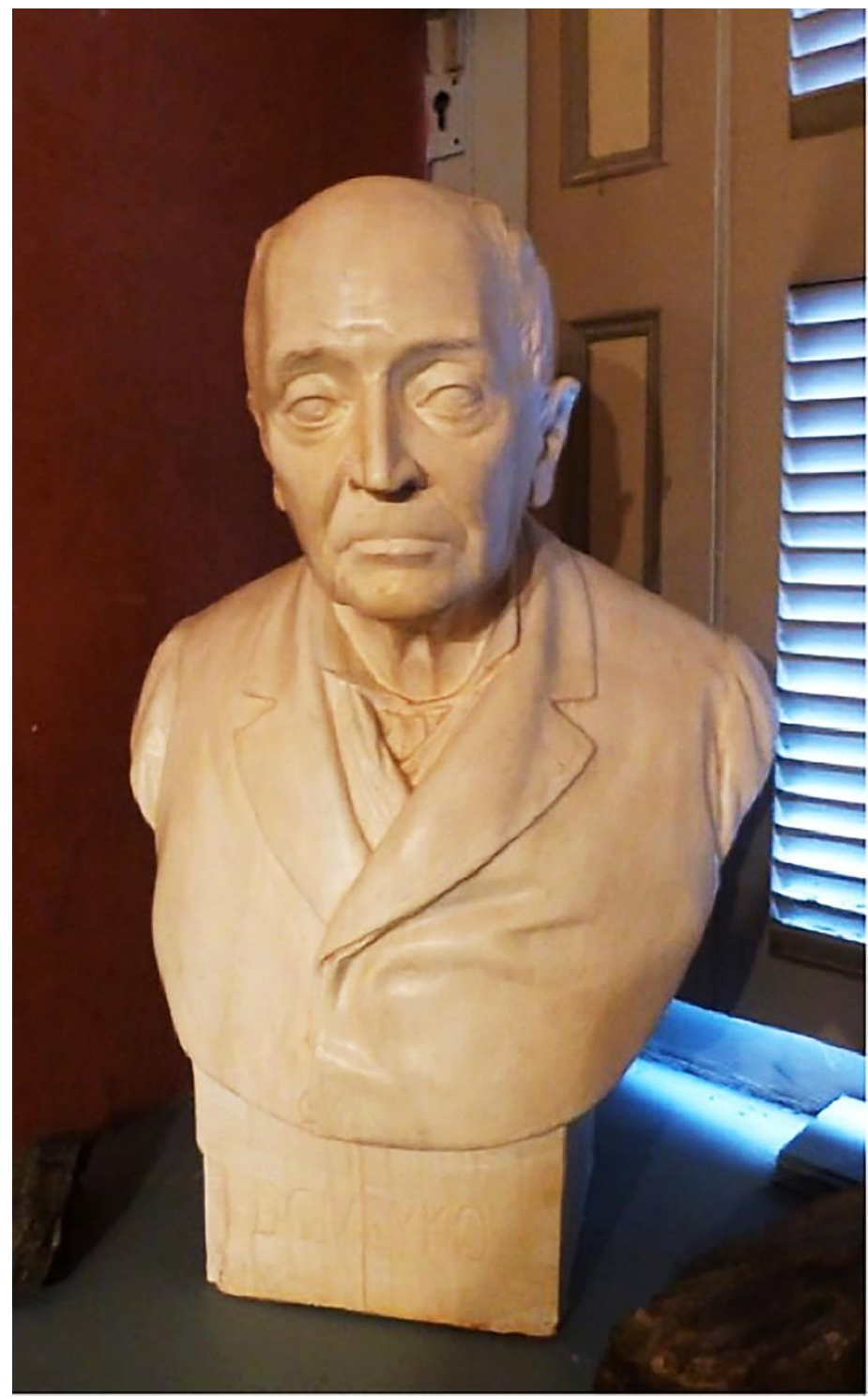

3. José Miguel Blanco, Busto de Ignacio Domeyko, 1884. Colección particular 